\title{
Pax 2 mutant mice display increased number and size of islets of Langerhans but no change in insulin and glucagon content
}

\author{
Maia Zaiko, Anne Estreicher, Beate Ritz-Laser, Pedro Herrera ${ }^{1}$, Jack Favor ${ }^{2}$, Paolo Meda ${ }^{1}$ and Jacques Philippe \\ Diabetes Unit, Department of Medicine, University Hospital Geneva, 24 Micheli-du-Crest, 1211 Geneva, Switzerland, ${ }^{1}$ Department of Morphology, \\ Geneva Medical School, 1211 Geneva, Switzerland and ${ }^{2}$ Institute of Mammalian Genetics, Geshäftsfürhung-Research Center for Environment and Health, \\ D-85764 Neuherberg, Germany \\ (Correspondence should be addressed to J Philippe; Email: jacques.philippe@hcuge.ch)
}

(M Zaiko and A Estreicher contributed equally to this work)

\begin{abstract}
Pax 2 is a paired box transcription factor expressed in a spatially and temporally restricted manner and its absence results in major developmental defects of the central nervous system, eyes, ears and urogenital system. We recently reported that Pax2 is expressed in pancreatic endocrine cell lines and adult islets of Langerhans and activates glucagon gene expression. We have shown here that the Pax2 gene is expressed during pancreas development as early as embryonic day 10.5. Its absence, as assessed in Pax $2^{1 \mathrm{Neu}}$ mutant mice, results in a two- to threefold increase in the average pancreas volume occupied by the islets in both heterozygous and homozygous mutant mice with a gene-dependent dosage effect. This increase, which is due to a change in the number of islets per unit pancreas volume and in the size of individual islets, is not accompanied by significant modification in the insulin or glucagon content of the pancreas, indicating that the content of these hormones per cell is decreased. We have concluded that Pax 2 may be implicated in the prenatal determination of the relative proportion of the endocrine and exocrine tissues of the pancreas.
\end{abstract}

European Journal of Endocrinology 150 389-395

\section{Introduction}

Growth and differentiation in the developing embryo are achieved by the accurate control of gene expression at any given stage. Transcription factors play a pivotal role in this process by controlling the expression of specific genes which are necessary for normal development. The pax gene family encodes transcription factors that have been implicated in the control of mammalian development $(1,2)$ and are characterized by the presence of a 128 amino acid DNA-binding domain, referred to as the paired box. In vertebrates, the nine members of the pax family can be classified in four groups based upon the presence of conserved structural domains, sequence homology and similar expression pattern $(3,4)$. Group I which comprises Pax1 and Pax9 bear the paired domain and a conserved octapeptide motif that can negatively regulate gene transcription by recruitment of Groucho corepressor proteins $(5,6)$. Pax 2 , Pax 5 and Pax 8 form group II which is specified by a paired domain, an octapeptide motif and a partial paired-class DNA-binding homeodomain. Group III, represented by Pax 3 and Pax7, contains a second DNA-binding motif, the homeodomain, downstream of the paired box and the octapeptide motif. Finally, the fourth group which includes Pax4 and Pax6 is characterized by the presence of the paired and entire homeodomain and the absence of the octapeptide. The Pax gene family has been shown to play important roles in the development of various structures and organs $(1-4)$.

Development of the endocrine pancreas is controlled by the group IV members, Pax 4 and Pax6. Targeted inactivation of the pax4 gene in mice results in the absence of insulin and somatostatin-producing $\beta$ - and $\delta$-cells whereas glucagon-producing $\alpha$-cells become more abundant (7). In contrast, Pax6 is necessary for the differentiation of pancreatic $\alpha$-cells (8).

We have recently shown that a member of the second group of the Pax family, Pax 2 , is expressed in pancreatic endocrine cell lines and transactivates the glucagon gene promoter through the G3 control element (9). The Pax 2 gene is expressed in a spatially and temporally restricted manner in several regions of the developing mouse embryo, including the mid-hindbrain boundary, the optic nerve, the spinal cord, the ears and the urogenital system $(10-12)$. Consistent with this expression pattern, targeted gene inactivation results in developmental defects of the eyes, kidneys, urogenital tracts and inner ear $(13,14)$. The function of Pax 2 in the pancreas is yet to be elucidated.

We report here that the Pax 2 gene is expressed at low levels during mouse pancreatic development as assessed by RT-PCR. Accordingly, we were unable to detect the 
Pax2 protein by immunolabeling pancreas sections. Analyses of the pancreas showed that the absence of Pax 2 in Pax $2^{1 \mathrm{Neu}}$ mutant mice (14) results in a twoto threefold increase in the total islet volume in both heterozygous and homozygous mutant mice with a gene-dependent dosage effect due to increased individual islet size and number per unit pancreas volume; however, we observed no significant change in the insulin or glucagon content of the pancreas. We have concluded that Pax2 may be implicated in the determination of the relative proportion of endocrine and exocrine tissues during pancreas development.

\section{Materials and methods}

\section{Animals}

All animals were kept under standard housing conditions with free access to water and food, and experiments were conducted according to the regulations of our institutional and state committees on animal experiments. Adult $\operatorname{Pax} 2^{1 \mathrm{Neu}}$ heterozygous mutant mice were crossed to produce wild-type, heterozygous and homozygous littermates. Because of the rapid neonatal death of the homozygous mutants, litters were delivered by laparotomy 1 day before the expected natural birth, i.e. at 18.5 days of embryonic development (E18.5). To this end, pregnant females were killed rapidly by cervical dislocation and the living pups released from uterine horns and anesthetized on a cold plate.

\section{Tissue sampling}

Anesthetized pups were placed under a binocular microscope for rapid microdissection of the entire pancreas and checking for the presence of cranial malformations and absence of kidneys (14). A caudal segment of each embryo was also cut and frozen for DNA extraction.

\section{Genotyping of embryos}

Genomic DNA was extracted from the caudal segments of embryos obtained from the cross between two Pax2 mice heterozygous for the Pax $2^{1 \mathrm{Neu}}$ mutation. Microsatellite markers D19Mit11 and D19Mit91 were PCR amplified according to the method of Favor et al. (14) using Taq DNA Polymerase (Life Technologies, Gaithersburg, MD, USA) and a $5 \mathrm{~min} 94^{\circ} \mathrm{C}$ denaturation followed by 35 cycles $\left(30 \mathrm{~s} 94^{\circ} \mathrm{C}\right.$ denaturation; $30 \mathrm{~s} 55^{\circ} \mathrm{C}$ annealing; $45 \mathrm{~s} 72^{\circ} \mathrm{C}$ extension) and a final extension of $5 \mathrm{~min}$ at $72^{\circ} \mathrm{C}$. Amplification products were separated in $2 \%$ agarose gels and visualized by ethidium bromide staining. The resulting PCR products obtained with D19Mit11 and D19Mit91 primers were of $146 \mathrm{bp}$ and $112 \mathrm{bp}$ for wild-type and $164 \mathrm{bp}$ and $140 \mathrm{bp}$ for mutant animals respectively.

\section{Pax 2 expression by RT-PCR analysis}

Total RNA was isolated from newborn and embryonic pancreata of BL6 $\times$ CBAJ mice using Trizol Reagent (Life Technologies) according to the manufacturer's specifications. In the early stages of development (E10.5E14.5), three to eight pancreata were pooled for RNA isolation, whereas starting from E17.5, single pancreas RNA isolations were performed. First-strand cDNA synthesis was performed with random hexamer primers and SuperScript II Reverse Transcriptase (Life Technologies) as recommended by the supplier. Amplification of Pax 2 cDNA fragments was achieved using the HotStarTaq DNA Polymerase (Qiagen) with the following amplification program: a $15 \mathrm{~min} 94^{\circ} \mathrm{C}$ denaturation followed by 35 cycles $\left(30 \mathrm{~s} 94^{\circ} \mathrm{C}, 30 \mathrm{~s} 55^{\circ} \mathrm{C}, 1 \mathrm{~min} 72^{\circ} \mathrm{C}\right)$ and a final extension of $5 \mathrm{~min}$ at $72^{\circ} \mathrm{C}$. PCR amplifications were carried out on single RNA preparations of E10.5 and E11.5, but on two to four independent RNAs from later stages. The primers used were $5^{\prime}$-CAGCCTTTCCACCCAACG-3' (forward, exon 4) and 5'-GTGGCGGTCATAGGCAGC-3' (reverse, exon 11) and their specificity for Pax 2 was tested in control amplifications using cDNAs from Pax4, Pax5, Pax6 and Pax8 (data not shown). PCR products were separated in $1 \%$ agarose gels and transferred overnight to NytranN nylon membranes (Schleicher \& Schuell, Keene, NH, USA). Membranes were u.v. cross-linked and hybridized with a radiolabeled internal $\operatorname{Pax} 2 \mathrm{~B}$ cDNA fragment which hybridizes to all Pax2 isoforms. All cDNAs were controlled with amplifications of the $\beta$-actin housekeeping gene (30 cycles) using primers sense $5^{\prime}$-cccagatcatgtttgagacc, antisense $5^{\prime}$-aggatcttcatgaggtagtc.

\section{Immunofluorescence}

The entire pancreas was immediately immersed in Bouin's fixative and processed as previously described for immunofluorescence labeling of insulin and glucagon (15). To immunolabel Pax2, pancreata (and kidney which was used as positive control) were frozen in liquid nitrogen, cryosectioned and incubated with polyclonal Pax2 antibodies (Berkeley Antibody Company, CA, USA) as previously reported (16).

\section{Morphometric analysis}

A total of 38,27 and 21 pancreata from seven litters were analyzed by standard morphometric procedures $(15,17)$ in embryos of the $+/+,+/-$ and $-/-$ genotype respectively at E18.5. Each pancreas was serially cut in $5 \mu \mathrm{m}$ thick sections, taken at a distance of $200 \mu \mathrm{m}$ from each other, and immunostained for insulin or glucagon. All analyses were performed on photographs taken at the original magnification of $\times 16$ (islet evaluation) or $\times 40$ (cell evaluation) and projected on a ACECAD Professional graphic tablet connected to a Quantimet Leica $500+$ (Leica, Cambridge, Cambs, 
UK) which was programmed for semiautomatic planimetric area measurements. Briefly, the volume density of $\beta$ - and $\alpha$-cells was determined by the ratio of their cell type area to that of the pancreas; islet size was determined by measuring the areas of individual islet profiles; the numerical density of islets was evaluated by scoring the total number of islets per unit pancreas area.

\section{Statistical analysis}

Statistical analysis of data was carried out using analysis of variance and $t$-test for independent samples $(\beta$ - and $\alpha$-cell density; islet numerical density), the median test and the Kolmogorov-Smirnov test (islet size), as provided by programs of the 06.01.02 Windows version of Statistical Package for Social Sciences (SPSS Inc., Chicago, IL, USA).

\section{Insulin and glucagon RIA and protein content}

A total of 11, 19 and 6 pancreata from five litters were assayed by standard biochemical procedures for insulin (18), glucagon and protein content in embryos of the $+/+,+/-$ and $-/-$ genotype respectively at E18.5. Briefly, the entire pancreas was microdissected, weighed wet, sonicated three times for $3 \mathrm{~s}$ (output control 2 of a Sonifier 250; Branton, Danbury, CT, USA) and extracted for $24 \mathrm{~h}$ at $4^{\circ} \mathrm{C}$ in $0.5 \mathrm{ml}$ acid-ethanol. Insulin content was evaluated using an RIA with a charcoal separation step, ${ }^{125} \mathrm{I}$ porcine insulin (SB-INS I-1; Sorin Biomedica, Saluggia, Italy) as tracer and rat insulin as standard (19). Glucagon was measured by RIA (LINCO Research, St Louis, MO, USA). Total protein content was evaluated using a Lowry assay (DC protein assay; BioRad, Glattbrugg, Switzerland).

\section{Results}

To study Pax2 gene expression in the developing pancreas, RT-PCR was performed on total RNA extracted from embryos at E10.5, 11.5, 12.5, 14.5 and 17.5 as well as from newborn BL $6 \times \mathrm{CBAJ}$ mice. At early stages of embryonic development (E10.5 and E11.5), total pancreata were used whereas from E12.5 onwards dorsal and ventral parts of the pancreas were collected separately. Rat brain tissue and human islets known to express Pax 2 were used as positive controls. PCR primers used for the amplification hybridized to all known Pax2 isoforms. After 35 cycles of amplification, Pax 2 fragments could be visualized by ethidium bromide staining and detected by Southern hybridization with a Pax2B internal fragment. Pax 2 was expressed as early as E10.5 in pancreas development and continued thereafter with, however, low mRNA levels during late embryonic development (Fig. 1).

In order to detect the Pax 2 protein in the developing pancreas, immunohistochemical analysis was performed using polyclonal Pax 2 antibodies, which give

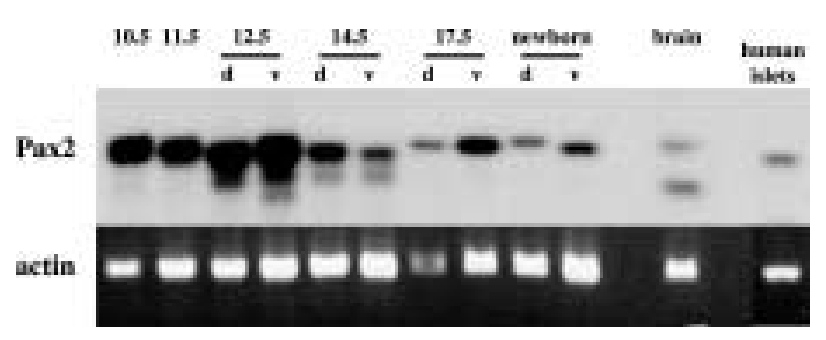

Figure $1 \mathrm{Pax} 2$ is expressed in the developing pancreas. Southern blot of Pax2 RT-PCR reactions from dorsal (d) and ventral (v) mouse developing pancreas, brain and human islets representative of several independent amplifications. Primers were specific for Pax2 cDNA inasmuch as they did not amplify other Pax cDNAs (data not shown). $\beta$-Actin cDNA amplification was performed as a control for the reverse transcription. Numbers at the top indicate embryonic days. The results are representative of several experiments and densitometric gel analysis of Pax2 and $\beta$-actin amplification products showed highest Pax2 expression early in development (E10.5-E12.5), which declined thereafter reaching about $25 \%$ of initial levels in newborn islets.

a positive signal in both embryonic kidney and the pancreatic endocrine cell lines, MIN6 and InR1G9, producing insulin and glucagon respectively (data not shown). However, using either a conventional fluorescein isothiocyanate-coupled secondary antibody or a biotin-streptavidin amplification system, we were unable to specifically detect $\operatorname{Pax} 2$ in the pancreas of E12.5-E18.5 mice (data not shown). These data suggest that Pax2 is expressed at low levels in the embryonic pancreas and that Pax 2 is not detectable by immunocytochemistry.

To investigate the role of Pax 2 in pancreatic development, we studied the mutant mouse line Pax $2^{1 \mathrm{Neu}}(14)$ characterized by a naturally occurring mutation, in which a $1 \mathrm{bp}$ insertion at the beginning of the paired domain of the pax 2 gene results in a frameshift. The truncated non-functional peptide coded by the mutated gene comprises only the first 21 amino acids identical to those of the wild-type protein. Islets of Langerhans, featuring an organization similar to that observed in wild-type littermates, were observed in the pancreas of heterozygous and homozygous $\operatorname{Pax} 2^{1 \mathrm{Neu}}$ mutant mice (Fig. 2). However, morphometric analysis indicated that the average pancreas volume occupied by the islets was increased two- and threefold in heterozygous $(P<0.06)$ and homozygous mutant mice $(P<0.04)$ respectively (Table 1$)$. This change was due to an increase in both the number of islets per unit pancreas volume $(P<0.01)$ and in the size of individual islets (Table 1 ). Thus, compared with that of wild-type controls, the area of the median islet profile was enlarged 1.4- and 2.1-fold in heterozygous $(P<0.05)$ and homozygous mutant mice $(P<0.007)$ respectively (Table 1$)$. This enlargement was confirmed by comparing the entire distribution of islets sizes, which were significantly $(P<0.002)$ different in the homozygous mutant and the wild-type groups (not shown). Evaluation of islet cells after immunostaining failed to reveal significant differences 

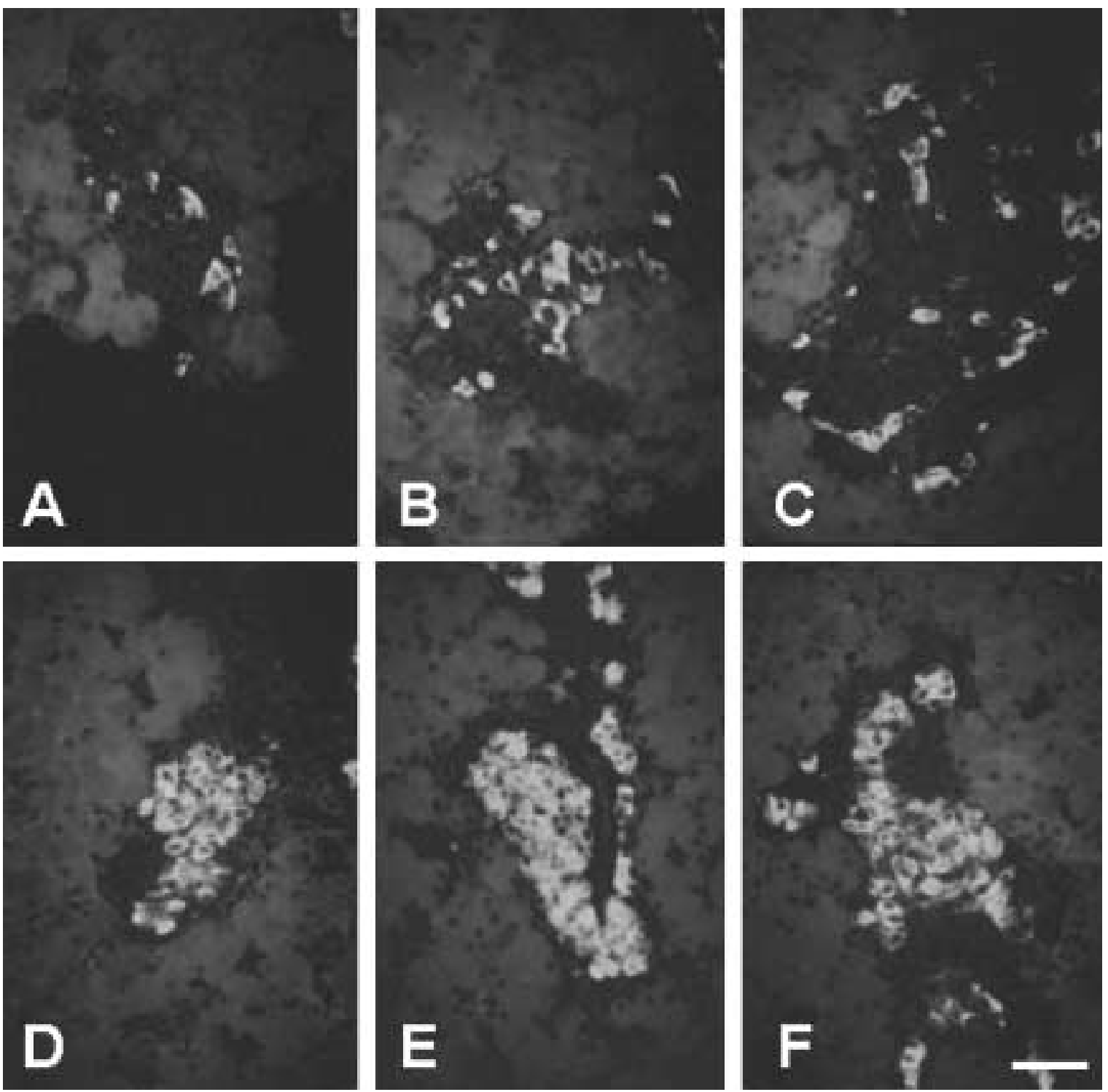

Figure 2 Pancreatic islets differentiate but are enlarged in Pax2 mutant mice. Islets of Langerhans of $(A$ and $D)$ wild-type, (B and $E)$ heterozygous and ( $C$ and $F$ ) homozygous Pax2 mutant mice were immunolabeled for either $(A-C)$ glucagon or (D-F) insulin. Islets of mutant mice featured a shape and a distribution of $\alpha$ - and $\beta$-cells similar to those of controls. However, they were enlarged in size, due to larger numbers of insulin-containing cells $(C)$. The bar represents $30 \mu \mathrm{m}$.

Table 1 Islets, $\beta$ - and $\alpha$-cells in the pancreata of E18.5 embryos. Relative volume and numerical density are expressed as means \pm S.E.M. values; $n_{\mathrm{p}}$ is the number of pancreata studied. Profile area is expressed as median value; $n_{\mathrm{i}}$ is the number of islets measured.

\begin{tabular}{|c|c|c|c|c|}
\hline \multirow[b]{2}{*}{ Embryo genotype } & \multirow[b]{2}{*}{$\begin{array}{c}\boldsymbol{\beta} \text {-cells } \\
\text { (\% pancreas volume) }\end{array}$} & \multirow[b]{2}{*}{$\begin{array}{c}\boldsymbol{\alpha} \text {-cells } \\
(\% \text { pancreas volume) }\end{array}$} & \multicolumn{2}{|l|}{ Islets } \\
\hline & & & Numerical density (number $/ \mathrm{cm}^{2}$ ) & Profile area $\left(\mu \mathrm{m}^{2}\right)$ \\
\hline $\begin{array}{l}\text { Wild-type } \\
+/- \\
-/-\end{array}$ & $\begin{array}{l}0.61 \pm 0.21\left(n_{p}=37\right) \\
1.20 \pm 0.29\left(n_{p}=25\right) \\
1.83 \pm 0.66^{\mathrm{e}}\left(n_{\mathrm{p}}=23\right)\end{array}$ & $\begin{array}{l}0.19 \pm 0.02\left(n_{\mathrm{p}}=18\right) \\
0.16 \pm 0.02\left(n_{\mathrm{p}}=19\right) \\
0.21 \pm 0.02\left(n_{\mathrm{p}}=12\right)\end{array}$ & $\begin{array}{l}2.25 \pm 0.53\left(n_{p}=37\right) \\
4.82 \pm 0.94^{\mathrm{c}}\left(n_{\mathrm{p}}=25\right) \\
5.23 \pm 1.33^{\mathrm{d}}\left(n_{\mathrm{p}}=23\right)\end{array}$ & $\begin{array}{r}14750\left(n_{\mathrm{i}}=102\right) \\
21159\left(n_{\mathrm{i}}=134\right) \\
31806^{\mathrm{a}, \mathrm{b}}\left(n_{\mathrm{i}}=96\right)\end{array}$ \\
\hline
\end{tabular}

${ }^{\mathrm{a}} P<0.05$ versus wild-type value (as determined by median test); ${ }^{\mathrm{b}} P<0.002$ versus wild-type distribution (as determined by the Kolmogorov-Smirnov test); ${ }^{c} P<0.01$ versus $-/-$ value (as determined by $t$-test); ${ }^{d} P<0.01$ versus wild-type value (as determined by $t$-test); ${ }^{e} P<0.04$ versus wild-type value (as determined by $t$-test). 
in the volume density of the glucagon-containing $\alpha$-cells between the three groups of mice studied (Table 1). In contrast, the volume density of the insulin-containing $\beta$-cells was significantly increased in both heterozygous $(P<0.06)$ and homozygous mutant mice $(P<0.04$; Table 1$)$.

Measurement of pancreas weight failed to show significant differences between the E18.5 embryos of the three genotypes studied (not shown). Evaluation of total protein and glucagon concentrations per unit volume of the glands did not reveal significant differences between groups and although insulin content was increased by $15 \%$ in the homozygous mutant mice, this difference was not statistically significant (Table 2).

\section{Discussion}

We recently reported that the pax 2 gene is expressed in pancreatic endocrine cell lines producing glucagon and insulin as well as in adult rat islets by RT-PCR. Furthermore, we detected the Pax 2 protein in these pancreatic endocrine cell lines (9). Pax 2 binds and transactivates the glucagon gene promoter through two control elements $G_{1}$ and $G_{3}$, whereas it has no known direct effect on insulin gene expression (9).

A potential role of Pax 2 in pancreatic development was hypothesized on the basis of its critical implication in the development of the central nervous system (CNS), the eyes, ears and kidneys (10-14). In this study, we have investigated the expression of the pax 2 gene in the developing pancreas. We have detected Pax2 mRNA as early as E10.5 with highest expression from E10.5 to E12.5 and low levels late during embryonic development. Since the exocrine pancreas develops from E12 to E14 with a major increase from E15 (20), then the pax 2 gene is likely expressed in the endocrine pancreas at least at the earliest stages. However, we were unable to detect the Pax 2 protein by immunolabeling embryonic pancreas using antibodies that gave strong specific signals in the developing kidneys. These results suggested that either Pax 2 is present in the pancreas in amounts too low to be detected by immunolabeling or that the cognate mRNA is not translated.

To clarify this issue, we analyzed the possible consequence of the absence of Pax 2 on pancreas development by studying the morphology and hormone content of the pancreas of the mutant mouse line $\operatorname{Pax} 2^{1 \mathrm{Neu}}(14)$.

The initial phase of pancreatic development, corresponding to evagination and bud formation occurs before E10.5 (21). Our results show that loss of Pax2 did not prevent the early development and morphogenesis of pancreatic islets, as evaluated by a normal cellular organization and shape of these micro-organs in E18.5 embryos. Furthermore, loss of Pax2 did not block the prenatal differentiation of $\beta$ - and $\alpha$-cells, as assessed by immunodetectable stores of insulin and glucagon, in both heterozygous and homozygous mutant mice. However, loss of Pax 2 did affect the quantitative, prenatal development of the endocrine pancreas. Thus, the number of islets per unit volume of pancreas, as well as the size of these micro-organs were found to be significantly increased in mutant mice. As a result, the relative volume islets occupied in the pancreas of these mice was increased compared with control value. This increase was twofold in heterozygous mice and threefold in homozygous mice, suggesting a gene dosage effect. Further analysis of islet cell types after immunolabeling showed that the islet enlargement was essentially accounted for by an increase in the volume of insulin-containing $\beta$-cells, whereas that of the glucagon-containing $\alpha$-cells was unaffected. The lack of effect of the Pax 2 mutation on $\alpha$-cell number and glucagon content was surprising since we previously identified Pax 2 as a transcriptional activator of the glucagon gene in pancreatic cell lines (9). Similarly, a recent study failed to detect an impact of the Pax $2^{1 \mathrm{Neu}}$ mutation on the formation of intestinal glucagon-producing cells (22). The discrepancy of these in vivo data and our previous in vitro results might be due to the nature of immortalized cell lines that have been used in our previous study. However, Pax2 may specifically affect $\beta$-cell number. Although to our knowledge no specific impact of the CNS on pancreas development has been described, we cannot exclude an indirect effect of the Pax $2^{1 \mathrm{Neu}}$ mutation through its general defects in the brain. Alternatively, the relatively mild pancreatic phenotype of $\operatorname{Pax} 2^{1 \mathrm{Neu}}$ mice could be due to functional redundancy of $\operatorname{Pax} 2$ and other Pax genes expressed in the endocrine pancreas. Pax 2 and Pax 6 expression has been shown to be interdependent in eye development (23) and Pax 5 is able to rescue most Pax 2 mutant effects in mice (24). We have

Table 2 Protein, insulin and glucagon concentration in the pancreata of E18.5 embryos. Values are means \pm S.E.M. values of the indicated number of measurements (one measurement per pancreas).

\begin{tabular}{|c|c|c|c|c|c|}
\hline \multirow[b]{2}{*}{ Embryo genotype } & \multirow[b]{2}{*}{ Proteins (mg/ml) } & \multicolumn{2}{|c|}{ Insulin } & \multicolumn{2}{|c|}{ Glucagon } \\
\hline & & $\mathrm{ng} / \mathrm{ml}$ & $\%$ of proteins & $\mathrm{ng} / \mathrm{ml}$ & $\%$ of proteins \\
\hline $\begin{array}{l}\text { Wild-type } \\
+/- \\
-1-\end{array}$ & $\begin{array}{l}2.72 \pm 0.47(n=11) \\
2.63 \pm 0.27(n=19) \\
2.75 \pm 0.31(n=6)\end{array}$ & $\begin{array}{l}1738 \pm 279(n=11) \\
1849 \pm 186(n=19) \\
2027 \pm 241(n=6)\end{array}$ & $\begin{array}{l}0.65 \pm 0.06(n=11) \\
0.73 \pm 0.06(n=19) \\
0.75 \pm 0.06(n=6)\end{array}$ & $\begin{array}{l}40.0 \pm 3.8(n=11) \\
78.4 \pm 8.5(n=19) \\
56.6 \pm 6.1(n=6)\end{array}$ & $\begin{array}{l}0.02 \pm 0.002(n=11) \\
0.03 \pm 0.004(n=19) \\
0.02 \pm 0.003(n=6)\end{array}$ \\
\hline
\end{tabular}


observed a $16 \%$ increase in the pancreas content of insulin which, however, failed to reach statistical significance in the group of homozygous mutant mice; despite this small increase our results have indicated that the average insulin content per cell is decreased in mutant compared with wild-type mice. Together, the data point to a role of Pax 2 in ensuring a quantitatively normal prenatal development of the endocrine pancreas.

In Drosophila, Pax2 is required for the development of multiple sensory organs and its expression appears to be regulated by the Notch signaling pathway (24). In mammals, during the period of growth and differentiation of the pancreatic primordia, a phase which critically requires $\operatorname{Pdx} 1$ activity as well as signals from the surrounding mesenchyme, the Notch signaling pathway appears to influence the choice between endocrine and exocrine fates (21, 25-27). The results reported here indicate that lack of Pax2 results in the expansion of endocrine cells. Taken together, we may speculate that Notch positively regulates Pax 2 to promote the exocrine and/or inhibit the endocrine differentiation of precursor cells within the mammalian pancreas, along with other transcription factors.

In conclusion, although $\operatorname{Pax} 2$ protein is expressed at low levels in the developing murine pancreas, it appears to play a role in determining the endocrine-exocrine fate in pancreatic precursor cells.

\section{Acknowledgements}

We are grateful to D Caille and A Charollais for excellent technical assistance. This work was supported by grants to J P (Swiss National Science Foundation 32-046816.96, Institute of Human Genetics and Biochemistry), to P M (Swiss National Science Foundation 31-53720.98, European Union QLG1-CT-1999-00516 and the Programme Commun de Recherche en Génie Médical) and to $\mathrm{P} \mathrm{H}$ (Swiss National Science Foundation 31-61724.00 and Juvenile Diabetes Research Foundation 1-2001-575). We also thank the Geshäftsfürhung-Forschungszentrum fuer Umwelt und Gesundheit, GmbH (GSF-National Research Center for Environment and Health) and its Institute of Human Genetics for providing the original Pax $-2^{1 \mathrm{Neu}}$ mutant mice.

\section{References}

1 Gruss P \& Walther C. Pax in development. Cell 199269 719-722.

2 Stuart ET, Kioussi C \& Gruss P. Mammalian Pax genes. Annual Review of Genetics 199428 219-236.

3 Dahl E, Koseki H \& Balling R. Pax genes and organogenesis. Bioassays $199719755-767$.

4 Mansuri A, Stoykova A \& Gruss P. Pax genes in development. Journal of Cell Science 199418 (Suppl) 35-42.
5 Lechner MS \& Dressler GR. Mapping of Pax-2 transcription activation domains. Journal of Biological Chemistry 1996271 21088-21093.

6 Eberhard D, Jiménez G, Heavey B \& Busslinger M. Transcriptional repression by Pax 5 (BSAP) through interaction with corepressors of the Groucho family. EMBO Journal $2000192292-2303$.

7 Sosa-Pineda B, Chowdhury K, Torres M, Oliver G \& Gruss P. The Pax 4 gene is essential for differentiation of insulin-producing beta cells in the mammalian pancreas. Nature $1998 \mathbf{3 8 6}$ 399-402.

8 Sander M, Neubüser A, Kalamaras J, Ee HC, Martin GR \& German MS. Genetic analysis reveals that PAX6 is required for normal transcription of pancreatic hormone genes and islet development. Genes and Development 199711 1662-1673.

9 Ritz-Laser B, Estreicher A, Gauthier B \& Philippe J. The paired homeodomain transcription factor Pax-2 is expressed in the endocrine pancreas and transactivates the glucagon gene promoter. Journal of Biological Chemistry $200027532708-32715$.

10 Dressler GR, Deutsch U, Chowdhury K, Nornes HO \& Gruss P. Pax2, a new murine paired-box-containing gene and its expression in the developing excretory system. Development $1990109787-795$.

11 Nornes HO, Dressler GR, Knapik EW, Deutsch U \& Gruss P. Spatially and temporally restricted expression of Pax 2 during murine neurogenesis. Development 1990109 797-809.

12 Terzic J, Muller C, Gajovic S \& Saraga-Babic M. Expression of PAX2 gene during human development. International Journal of Developmental Biology 199842 701-707.

13 Torres M, Gomez-Pardo E, Dressler GR \& Gruss P. Pax-2 controls multiple steps of urogenital development. Development 1995121 4057-4065.

14 Favor J, Sandulache R, Neuhauser-Klaus A, Pretsch W, Chatterjee $\mathrm{B}$, Senft E et al. The mouse Pax2 (1Neu) mutation is identical to a human PAX2 mutation in a family with renal-coloboma syndrome and results in developmental defects of the brain, ear, eye, and kidney. PNAS 199693 13870-13875.

15 Charollais A, Serre V, Mock C, Cogne F, Bosco D \& Meda P. Loss of alpha 1 connexin does not alter the prenatal differentiation of pancreatic beta cells and leads to the identification of another islet cell connexin. Developmental Genetics 199924 13-26.

16 Dressler GR, Wilkinson JE, Rothenpieler UW, Patterson LT, Williams-Simons L \& Westphal H. Deregulation of Pax2 expression in transgenic mice generates severe kidney abnormalities. Nature $1993 \mathbf{3 6 2} 65-67$.

17 Stefan Y, Meda P, Neufeld M \& Orci L. Stimulation of insulin secretion reveals heterogeneity of pancreatic B cells in vivo. Journal of Clinical Investigation $1987 \mathbf{8 0} 175-183$.

18 Charollais A, Gjinovci A, Huarte J, Bauquis J, Nadal A, Martin F et al. Junctional communication of pancreatic beta cells contributes to the control of insulin secretion and glucose tolerance. Junctional communication of pancreatic beta cells. Journal of Clinical Investigation 2000106 235-243.

19 Meda P, Bosco D, Chanson M, Giordano E, Vallar L, Wollheim C et al. Rapid and reversible secretion changes during uncoupling of rat insulin-producing cells. Journal of Clinical Investigation $199086759-768$.

20 Edlund H. Transcribing pancreas. Diabetes $1998471817-1823$.

21 Edlund H. Developmental biology of the pancreas. Diabetes 2001 50 (Suppl 1) 55-59.

22 Flock G \& Drucker DJ. Pax-2 activates the proglucagon gene promoter but is not essential for proglucagon gene expression or development of proglucagon-producing cell lineages in the murine pancreas or intestine. Molecular Endocrinology 200216 2349-2359.

23 Schwarz M, Cecconi F, Bernier G, Andrejewski N, Kammandel B, Wagner M et al. Spatial specification of mammalian eye territories by reciprocal transcriptional repression of Pax2 and Pax6. Development $20001274325-4334$. 
24 Bouchard M, Pfeffer P \& Busslinger M. Functional equivalence of the transcription factors Pax 2 and Pax 5 in mouse development. Development 2000127 3703-3713.

25 Kavaler J, Fu W, Duan H, Noll M \& Posakony JW. An essential role for the Drosophila Pax2 homologue in the differentiation of adult sensory organs. Development 1999126 2261-2272.

26 Apelqvist A, Li H, Sommer L, Beatus P, Anderson DJ, Honjo T et al. Notch-signaling controls pancreatic cell differentiation. Nature $1999400877-881$.
27 Jensen J, Pedersen EE, Galante P, Hald J, Heller RS, Ishibashi M et al. Control of endodermal endocrine development by Hes-1. Nature Genetics $2000 \mathbf{2 4} 36-44$.

Received 4 June 2003

Accepted 21 November 2003 